\title{
TRANSFERÊNCIA CUULTURAL EM TRADUÇÃO: CONTEXTUALIZAÇÃO, DESDOBRAMENTOS, DESAFIOS
}

\author{
João Azenha Junior*
}

\begin{abstract}
RESUMO: Este artigo discute alguns elementos pertinentes à compreensão da noção de "transferência cultural" em sua relação com a tradução. Para a definição de um contexto, as considerações remetem à década compreendida entre 1970 e 1980, aproximadamente, período que a historiografia dos Estudos da Tradução costuma reservar a uma mudança de paradigma operada em tradução: a primazia do texto a ser traduzido cede lugar paulatinamente às condições de recepção do texto traduzido. Tal mudança, levada a cabo pari passu com evoluções correlatas em áreas afins, atingiu a reflexão sobre tradução como um todo. Embora mais facilmente perceptivel (e aceitável) no domínio da tradução literária, a noção de transferência cultural passa a ser elemento fundamental também da tradução de textos técnicos e científicos. Sensibilizar estudantes de tradução para algumas características dessa questão e oferecer um breve panorama das premissas teóricas para o seu tratamento em trabalhos de grau são os objetivos deste estudo.
\end{abstract}

PALAVRAS-CHAVE: Transferência cultural; Textos literários; Textos técnicos e científicos; Tradução.

ABSTRACT: This article deals with some elements related to the notion of "cultural transfer" in translation. In order to draw the borders of a context, the considerations go back to

* Prof. Dr. do Departamento de Letras Modernas (DLM) da Universidade de São Paulo. 
the decade between 1970 and 1980, approximately, a period traditionally reserved by the historiography of Translation Studies for a paradigm change in Translation Studies: the primacy of the text to be translated slowly loses terrain to the reception conditions of the translated text. Such a change, carried out pari passu with other analog evolutions in correlated areas of knowledge, reached translation as a whole. Although more easily identified (and acceptable) in the domain of literary translation, the notion of cultural transfer becomes also a fundamental element in the translation of scientific and technical texts. The present article aims at sensitizing translation students for some features of this question by offering a panorama of the theoretical premises for its treatment in academic works.

KEYWORDS: Cultural transfer; Literary texts; Technical texts; Scientific texts; Translation.

\section{Um cenário, dois momentos}

A despeito de o vínculo entre tradução e cultura não ser novo do ponto de vista da historiografia da tradução ${ }^{1}$, o conceito de "transferência cultural" 2 em tradução é relativamente recente. O termo ganhou relevância a partir de meados da década de 1970 no bojo da chamada Escola Funcional-Cultural dos Estudos da Tradução na Alemanha - também conhecida como Skopostheorie -; foi encampado um pouco mais tarde, entre

1 Já no séc. XIX, por exemplo, ainda que numa acepção diversa, mais restrita da que se tem hoje, a noção de transferência cultural aparece associada à noção mesma de tradução vigente no Romantismo alemão, entendida esta como via de acesso e de apropriação (Aneignung) de um "bem" que está distante temporal, social e geograficamente do momento da tradução.

2 Na concorrência com outras designações, como "tradução" e "translação", o termo "transferência" tem a vantagem de ser mais genérico, menos comprometido com uma corrente teórica específica dos Estudos da Tradução ao longo da História.

TradTerm, 16, 2010, p. 37-66 
meados da década de 1980 e fins dos anos de 1990, pelo chamado Grupo de Göttingen ${ }^{3}$ e aplicado sistematicamente à tradução literária, através de estudos de caso inspirados pelos Estudos Descritivos da Tradução e pela Teoria dos Polissistemas ${ }^{4}$.

Considerada a partir do momento mesmo em que passa a ser usada mais sistematicamente, a noção de "transferência cultural" em tradução está associada a uma mudança de ponto de vista, a uma mudança de paradigma que, na historiografia dos Estudos da Tradução, ficou conhecida como "virada cultural". Por força dessa mudança, o centro de interesse na reflexão sobre o traduzir e sobre a avaliação de traduções desloca-se de uma visão de tradução centrada na língua ${ }^{5}$, cujas raízes remetem à passagem do séc. XVIII para o séc. XIX ${ }^{6}$ sistematizada pela influência do estruturalismo, para uma visão que, seguindo os passos da teoria da comunicação, concebe cultura como um fenômeno abrangente, que abarca todas as manifestações de um povo num ponto específico de um eixo espaço-tempo, estabelece uma relação de condicionantes recíprocas entre linguagem e cultura e inclui os elementos constitutivos da comunicação numa dada situação: emissor, receptor, meio entre outros ${ }^{7}$.

Trata-se, é bem verdade, de dois momentos, cujas raízes podem ser buscadas historicamente, mas que - aliás, como tudo

3 Cf. a seção Transferência cultural e textos literários, adiante.

4 Para uma introdução aos conceitos, modelos e métodos dessas duas vertentes, cf. Toury 1980, 1985 e 1995; Even-Zohar, 1978 e 1990; Hermanns, 1999; Munday, 2001; Cruz, 2007, entre outros.

5 Emprego com cuidado a expressão, não sem chamar a atenção para o fato de que, retrospectivamente, a noção de lingua a ser considerada aqui é aquela vigente na década de 1970.

6 Basta lembrar a reflexão de Wilhelm von Humboldt em sua Introdução a Agamênon para encontrarmos a noção de linguagem como possuindo um plano de realização, marcado pelos "usos comuns da vida", de um lado, e, de outro, uma esfera de potencialidades, a partir da qual se pode "exprimir tudo, as coisas mais altas e profundas, as mais fortes e delicadas" (Heidermann, 2001:91 ss.).

7 Para um detalhamento dessa etapa de transição no ambiente alemão, cf., por exemplo, Snell-Hornby (1988; 1989; e 2006); Reiss (1983), Reiss e Vermeer (1984), Nord (1993). 
na reflexão sobre a linguagem - não devem ser vistos como fenômenos isolados e excludentes. Afinal, antes de se oporem frontalmente, esses dois momentos constituem uma etapa de evolução marcada preponderantemente por uma mudança de olhar e, não menos importante, pela influência de evoluções paralelas em áreas afins, com as quais a tradução vinha e vem mantendo relações recíprocas e frutíferas desde os seus primórdios: os estudos da linguagem e a filosofia, só para citar dois exemplos.

Naquele que podemos chamar de um primeiro momento, prevalece o olhar retrospectivo, quer dizer, o texto de partida é considerado o parâmetro por excelência para o estabelecimento dos critérios de avaliação da tradução, que são definidos por comparação. Como decorrência dessa mirada retrospectiva, ganha destaque a noção de equivalência ${ }^{8}$, a busca por "material textual equivalente" (Catford, 1980:22; $1^{\text {a }}$ ed. 1965). Também como decorrência disso, prevalece a visão normativa nas considerações sobre tradução: um sujeito, que se julga isento em todo o processo de constituição (e de comparação) de sentidos, faz uso dessa posição de "não envolvimento", transcodifica, a partir de um locus privilegiado, uma dada sequência significativa, e decide sobre o que pode (ou não) substituí-la em outra língua. Não é de se admirar, portanto, que, na prática, a noção de competência tradutória coincida com a de competência linguística: tanto melhor será a tradução quanto maior for o domínio do tradutor sobre as linguas da(s) qual(is) e para a(s) qual(is) tradu $z^{9}$.

No segundo momento, ganha primazia o olhar prospectivo: a ênfase se desloca do texto de partida para o complexo da recepção, quer dizer, não apenas se tem em vista um receptor ancorado histórica e geograficamente, mas também se atenta, por exemplo, para a acomodação do texto traduzido às normas e

8 Sobre a noção de equivalência, tal como desenvolvida na chamada Escola de Leipzig, cf., entre outros, os textos organizados por Cardoso et al (2009).

9 Sobre a gênese do sentido e as visões de tradução vigentes à época, cf. em especial os trabalhos de Mounin (1975), Ladmiral (1979) e Catford (1980).

TradTerm, 16, 2010, p. 37-66 
convenções da cultura receptora. Tal ideia questiona a posição de isenção do sujeito intermediador desse processo, principalmente porque a leitura que se faz do Outro não mais depende apenas dos conhecimentos de língua; em sua complexidade, ela é singular, única: ao se estabelecerem os parâmetros para a acomodação do texto traduzido, o sujeito se identifica e revela sua maneira de ver. Como decorrência disso, a prescrição deixa de ter a primazia e o processo todo - texto de partida, texto traduzido, considerações sobre a recepção etc. - mais descreve do que prescreve.

Da mesma forma, os critérios de avaliação são incrementados e se deslocam das características peculiares do texto de partida para o estudo da função que o texto traduzido deve assumir na cultura receptora. Tal fato traz consequências imediatas para a noção de competência tradutória: da condição de coincidente com a competência linguística, a competência tradutória se distingue por forçosamente incluir os diversos elementos que são responsáveis pela otimização da comunicação. $\mathrm{E}$, nesse sentido, ela remete forçosamente para frente, quer dizer, para a reflexão preparatória que visa à recepção, deslocando o tradutor, assim, de uma posição acima e à parte do processo, para a do interior deste.

Tal mudança de olhar afeta a tradução como um todo e não apenas parte dela, já que a mudança no olhar está associada ao modo mesmo como, num dado momento da História, se passa a conceber a geração de sentido em linguagem. Sob esse ponto de vista, qualquer diferenciação valorativa entre diferentes tipos de tradução não é produtiva para a discussão:

(...) ao trabalho de discussão sobre uma visão de tradução mais abrangente deve aliar-se um trabalho de eliminação da noção pré-concebida, segundo a qual alguns tipos de texto são mais importantes do que outros. Somente através da não-diferenciação qualitativa entre os tipos de texto (...) é que teria sido dado o primeiro passo na direção de um elemento comum capaz de conciliar pontos de vista diversos. (Azenha, 1999:61)

Sabemos, contudo, que - na teoria como na prática da tradução - é clássica a divisão entre textos literários, de um lado, e 
textos pragmáticos ou utilitários, de outro. Da mesma forma, sabemos que há uma discrepância entre o que se diz (quer dizer, se teoriza) e o que se aplica (quer dizer, se pratica) em relação a um e a outro exemplar textual dessas duas grandes e indefinidas categorias. Um rápido passar de olhos pela historiografia da tradução revela que a ênfase recai sobre a primeira categoria: a história da tradução no Ocidente é a história de traduções literárias e da Bíblia. Com efeito, só muito esporadicamente a tradução de textos técnicos e científicos foi abordada, em tempos passados, de forma mais ou menos sistemática ${ }^{10}$.

Assim, questões de tradução atinentes a outros tipos de textos, que não os literários, sempre foram consideradas, na perspectiva da História, em desvantagem em relação à tradução de literatura. Contrariamente à tradução de literatura e de textos religiosos, na qual seriam flagrados, de forma mais evidente, o vínculo com a História, com o pensamento, com a profissão de fé, com a forma como cada um lê e interpreta o mundo, tudo isso ganhando corpo na dimensão criativa do uso da lingua, a tradução de outros tipos de texto estaria voltada para propósitos mais específicos e imediatos, para situações de comunicação de contornos mais bem definidos; numa palavra: para a prática do dia-a-dia das relações do comércio, das ciências, da esfera política. Não é sem razão, portanto, que Fluck (1998:73) observa que "as reflexões acerca de um processo de translação ${ }^{11}$ voltado especificamente para textos de especialidade ${ }^{12}$ foram engendradas primeiramente por práticos".

Nesse ponto, a noção de transferência cultural, ao atingir o processo de tradução como um todo, possui vocação para re-

10 Por exemplo, no tratado Sobre os diferentes métodos de traduzir, apresentado por Friedrich Schleiermacher à Academia Real de Berlim em 1813 (cf. Heidermann, 2001).

11 O termo "translação", cunhado no interior da escola Funcional-Cultural dos Estudos da Tradução, pode ser entendido como um termo hiperônimo que engloba a tradução (escrita) e a interpretação (oral).

12 Designação atual e mais consensual, que abarca os tipos de textos técnicos e científicos. Neste ensaio, deixo de lado a diferenciação entre textos técnicos (de natureza mais instrucional) e científicos (em que prevalece uma estrutura argumentativa).

TradTerm, 16, 2010, p. 37-66 
meter a discussão a uma camada mais profunda, a um ponto para além das diferenças de superfície marcadas por distinções de tipologia textual. Mas se, de um lado, tal vocação é capaz de restituir à tradução um tratamento mais homogêneo, de outro, isso não se dá sem que se lancem desafios ao pesquisador e ao estudante de tradução. Afinal, a ancoragem das considerações num patamar mais genérico impõe tomada de decisões com vistas à construção de um instrumental de trabalho capaz de definir procedimentos afinados com essa perspectiva e adequados ao trabalho com o caso específico. Um breve panorama dessa problemática é o que se pretende apresentar a seguir. Primeiramente serão abordadas algumas relações entre a noção de transferência cultural e os textos de especialidade; na seqüência, o foco das considerações será deslocado para os textos literários.

\section{Transferência cultural e textos de especialidade}

A inclusão dos textos de especialidade na agenda das questões de transferência cultural não é apenas decorrência natural da evolução dos Estudos da Tradução, mas uma reivindicação pertinente. Fala a seu favor, para começar, a sucessão de eventos históricos que marcaram o séc. XX - as duas grandes guerras, a fundação de organismos internacionais e o aumento na circulação de pessoas, só para citar alguns exemplos -, bem como o intercâmbio de informações veiculadas no ambiente de espaços interculturais nas áreas da ciência e da tecnologia, do comércio e do mundo das finanças. Tais fatos geraram um aumento considerável no volume de traduções desses tipos de texto, que em muito suplanta o volume de traduções literárias, e levaram a uma reflexão mais sistematizada sobre a tradução de linguagens de especialidade associada ao conceito de transferência cultural, seja pela sua importância mesma para o desenvolvimento de setores fundamentais da existência humana, seja por força de situações de desconforto, por falhas na comunicação e por malentendidos, muitas vezes de consequências imprevisíveis.

Sobre os imperativos da prática e sobre a reflexão acerca da descrição de linguagens de especialidade e da tradução de textos gerados no interior delas, Fluck (1998) observa:

TradTerm, 16, 2010, p. 37-66 
Um interesse público mais duradouro pela função e diversidade da comunicação específica entre ciência e prática é, contudo, um fenômeno mais recente, a ser relacionado tanto com a observação da linguagem a partir de uma perspectiva estilístico-funcional (a "Escola de Praga"), quanto com o surgimento, em decorrência desse ângulo de observação, da chamada lingüística da economia nos anos de $1930 .{ }^{13}$ (Fluck, 1998:73)

A observação de Fluck corrobora o que se vem expondo até aqui: o momento fundador de uma nova perspectiva de abordagem da tradução - nesse caso, a inclusão dos textos de especialidade na agenda da reflexão sobre tradução e cultura - flagra, de um lado, o vínculo dessa perspectiva com imperativos ditados pelos tempos e, de outro, a filiação dessa nova perspectiva com a corrente de pensamento sobre questões de linguagem vigente nesse mesmo momento fundador.

Isso não significa, porém, que se tenha estabelecido, desde o início, um intercâmbio sistemático de ideias entre as vertentes teóricas da tradução centradas no texto literário, de longuíssima tradição, e as primeiras tentativas de se circunscrever e sistematizar essa nova perspectiva relacionada à tradução de textos de especialidade. Com efeito, um tempo de maturação seria ainda necessário para se relacionar o que se pensa sobre e se aplica numa subárea específica dos Estudos da Tradução para o processo de tradução entendido como um conjunto.

Nesse sentido, tentativas de se construírem pontes que buscavam elementos característicos para a tradução em si, para além da divisão clássica entre diferentes tipos de textos (e de traduções), foram empreendidas no ambiente de expressão alemã principalmente a partir da década de 1980 por Snell-Hornby ${ }^{14}$ : são os tempos de uma "nova orientação" (Neuorientierung) dos Estudos da Tradução, cujo objetivo é fundar uma "visão integrada", na esteira das tentativas de se estabelecerem os contornos

13 Salvo indicação em contrário, as traduções de citações em língua estrangeira são minhas.

14 Cf. Snell-Hornby (1986; 1988; 1989; 2006).

TradTerm, 16, 2010, p. 37-66 
para os Estudos da Tradução como campo disciplinar ${ }^{15}$. Mais uma vez, o principal ponto de partida para tal reorientação estava, do ponto de vista teórico, no alinhamento dos Estudos da Tradução com novas abordagens dos Estudos Linguísticos ${ }^{16} \mathrm{e}$, do ponto de vista da prática da tradução, sobretudo na constatação de que os textos de especialidade, longe de constituírem uma categoria à parte, definida a partir de elementos textuais específicos, são fenômenos basicamente híbridos e resistem a sistemas de categorizações tipológicas tradicionais.

Desse modo, os textos de especialidade não podem ser definidos apenas a partir de uma antiga dicotomia sintetizada na fórmula "texto técnico (ou científico, ou pragmático ou utilitário) vs. texto literário", nem apenas a partir de categorizações tripartites como a de Reiss (1983) - textos referenciais, expressivos e operativos (apelativos) -, fundadas nos elementos integrantes da comunicação. Os textos de especialidade constituem, isso sim, um complexo heterogêneo e aberto, de contornos esmaecidos, no qual se pode verificar um constante evoluir de textos mais prototípicos para outros, já localizados numa zona de fronteira com outro tipo textual (Snell-Hornby 1988) ${ }^{17}$. Como vimos há pouco, na esteira de uma mudança de olhar, não são os elementos linguísticos intrínsecos que definem os limites das categorizações, mas sim a relação que se estabelece entre esses mesmos elementos e tudo o que cerca e define a comunicação numa dada situação e numa dada cultura.

No que se refere ao desenvolvimento dos estudos sobre as linguagens de especialidade na sua relação com a terminologia,

15 Sobre os reflexos dessa mudança de paradigma para os estudos da tradução técnica no Brasil cf. Azenha (1999), Aubert (2001), Bessa (2003) e Barbosa (2004), entre outros.

16 Refiro-me aqui, mais especificamente, à chamada "virada pragmática" dos Estudos Linguísticos (cf. Koch, 2004, por exemplo)

17 Paralelos, com os contornos e propósitos dos Estudos Descritivos da Tradução e com a Teoria dos Polissistemas, seriam aqui não apenas desejáveis, como também, a meu ver, necessários para uma aproximação mais eficaz entre as duas vertentes de pesquisa dos Estudos da Tradução. Tais paralelos, contudo, extrapolariam os objetivos deste ensaio introdutório.

TRADTERM, 16, 2010, p. 37-66 
mais sistematicamente desenvolvidos na segunda metade do séc. $\mathrm{XX}$, uma reorientação correlata pode ser observada: a questão do termo, considerado via de regra o traço distintivo por excelência das linguagens de especialidade, evolui paulatinamente de uma visão, digamos, estática de terminologia (como nos preceitos da Teoria Geral da Terminologia desenhada por Eugen Wüster nos anos de 1970 sob a égide do estruturalismo ${ }^{18}$ ) para uma concepção de termo que inclui deslocamentos de perspectiva que variam de cultura para cultura e definem "incongruências conceituais interculturalmente condicionadas" (Schmitt, 1989: 54) ${ }^{19}$.

Sob esse novo prisma, a divisão estanque entre conceito e nomenclatura, entendida como estável em vista do caráter normativo que marcou os primeiros tempos da terminologia e da almejada univocidade no tratamento do léxico de especialidade, aos poucos cede lugar a uma visão de termo que flagra o vínculo deste último não apenas com uma área de especialidade, mas também com situações de uso no interior dessas áreas e fora delas, ditadas pela subordinação da comunicação em e entre áreas de especialidade a normas e convenções, descompassos do saber, diferentes metodologias na constituição dos termos, entre outros ${ }^{20}$. Faulstich (2001) comenta:

Na década de 80 , surge uma nova atitude em relação à variação em terminologia. A meta era entender a variação como um fenômeno de língua, de usos e de natural ocorrência nas linguagens de especialidade. Entender, enfim, que terminologia é disciplina de ordem social. (Faulstich, 2001:19)

Cabré et alii (1998) atestam essa mudança de paradigma na terminologia e associam-na ao vínculo dessa área de estudos com outros desenvolvimentos em áreas afins e com o modo mes-

18 Para um panorama do pensamento de Wüster, cf., por exemplo, Faulstich (2001:13 ss.)

19 Sobre esse aspecto, cf. Schmitt (1986) e Azenha (1994; 1999).

20 Para um aprofundamento dessa linha evolutiva, cf., por exemplo, Krieger (1998), Krieger e Maciel (2001) e Krieger e Finatto (2004).

TradTerm, 16, 2010, p. 37-66 
mo de se pensarem as formas de produção de sentido em linguagem:

\begin{abstract}
A terminologia mudou muito nos últimos dez anos. Esta mudança verificou-se tanto na prática terminológica, quanto na teoria que a ela subjaz. Certo é que é cada vez maior o número de especialistas em terminologia que manifestam abertamente sua insatisfação ao seguirem, sem pequenas modificações, os princípios da teoria geral clássica e que destacam o fato de que entre a teoria estabelecida e as aplicações que se têm levado a cabo existem desajustes importantes; e isso por diferentes razões. A fim de explicarmos a importância e o sentido desta virada no enfoque da terminologia, não podemos esquecer o panorama geral e as mudanças que se produziram nas áreas afins que a configuram como uma interdisciplina: a lingüística, a filosofia e a comunicação. (Cabré et alii, 1998:33-34, grifo meu)
\end{abstract}

Nesse contexto, Cabré menciona alguns fenômenos que, a seu ver, teriam contribuído para uma revisão do conceito de terminologia, de seu escopo e arcabouço metodológico: a globalização do mercado, o "crescimento geográfico e social da ciência e da tecnologia" (Cabré, 1998:34, grifo meu) e a "explosão da técnica e da informação" (idem: 34). Não é difícil perceber que se trata, aqui, de um movimento que busca conciliar forças opostas: o movimento centrípeto gerado pelo controverso conceito de globalização, de um lado, e, de outro, características distintivas da evolução do saber em áreas específicas, dependendo do lugar em que tal conhecimento se desenvolve. Do reconhecimento e da aceitação da diversidade resulta, então, o imperativo de se reverem conceitos e métodos. Um desses aspectos revistos ao longo dessa linha evolutiva diz respeito à noção mesma de texto de especialidade. No momento em que a lingua passa a ser vista como um sistema ancorado culturalmente e constituído por vários subsistemas (as linguagens de especialidade sendo um deles), no momento em que a prática da tradução de textos de especialidade evidencia desajustes e incongruências para além do léxico de especialidade, a primazia deste último 
como traço distintivo da competência tradutória no âmbito das linguagens de especialidade passa a concorrer com outros estratos constitutivos do fenômeno "texto". Tal deslocamento de enfoque é o que se pode observar nas três citações que se seguem, distantes entre si por um intervalo de aproximadamente dez anos:

Ouve-se, às vezes, exprimir a opinião de que, na tradução técnica, os problemas de estilo carecem de importância. De certo, a tradução técnica não é, de modo algum, um exercício literário, mas, sendo o estilo na verdade a maneira de exprimir o pensamento por meio dos recursos da língua, os mesmos problemas hão de surgir sempre, qualquer que seja o setor no qual se exerce a atividade do tradutor. (Maillot, 1975:75; $1^{\mathrm{a}}$. ed. Francesa: 1969, Trad. Paulo Rónai)

No início, a atenção se concentrava quase que exclusivamente no vocabulário técnico e, mais especificamente, na terminologia. Depois, pouco a pouco, a sintaxe passou a ser alvo de estudo. Atualmente, o interesse volta-se cada vez mais para o texto técnico como um todo estrutural e funcional. (Hoffmann, 1988:91)

Com o desenvolvimento da pesquisa das linguagens de especialidade "do termo para o texto" ganham destaque hoje princípios interdisciplinares, bem como aspectos textual-analíticos (relacionados ao tipo de texto e de discurso) e estilístico-pragmáticos e interculturais da comunicação numa área de especialidade, que podem ser de utilidade para a análise do texto de partida e de chegada na tradução do texto de especialidade (Fluck, 1998:73)

Desse modo, se as condicionantes culturais eram menos transparentes no domínio exclusivo do termo, o redimensionamento das questões atinentes à tradução de textos de especialidade, sob a perspectiva da noção de transferência cultural, evidencia outros níveis de interferência igualmente importantes e que demandam, assim, sua inclusão na competência tradutória dos profissionais atuantes nesse domínio: a sujeição a conven-

TradTerm, 16, 2010, p. 37-66 
ções (por exemplo, nos termos de abertura e fechamento da comunicação empresarial), a normas (por exemplo, a divisão e a disposição das partes de contratos bilaterais), a subordinação a instituições (por exemplo, a disposição das partes constituintes das bulas de remédio, que dependem da aprovação de órgãos ligados ao Ministério da Saúde), assim como - do nível do texto para o da interação discursiva - o emprego de fórmulas de tratamento, a presença explícita ou não do enunciador (impessoalidade do discurso), os mecanismos de compactação de informação (e, para a tradução, as consequências disso em face das diferenças entre as línguas envolvidas), o tratamento dos elementos não verbais, as ênfases para temas que são caros a uma dada cultura (por exemplo, questões de segurança e de meio ambiente, bem como o controle da incursão na vida privada das partes contratantes em função de normas que regularizam o uso de dados informatizados). Todas essas instâncias - ou dimensões, como as denomina Oksaar (1988) - flagradas na conceituação do texto e do discurso de especialidade retroalimentam, por sua vez, tanto a terminologia, quanto a tradução de textos de especialidade ${ }^{21}$.

A exploração dessas camadas ou dimensões resultou numa revisão do conceito de linguagem de especialidade ${ }^{22}$, de modo que a distinção tradicional entre textos técnicos e científicos, de um lado, e literários, de outro, não mais pode se sustentar, ao menos no plano teórico: as diferenças entre as traduções de diferentes tipos de textos são distinções de grau, mas não de natureza ${ }^{23}$.

A partir desse ponto, e a exemplo do que ocorre com todas as vertentes dos Estudos da Tradução no séc. XXI, também aqui as pesquisas sobre a tradução de textos de especialidade foram selando parcerias com diversas áreas. Talvez a principal dessas parcerias tenha sido com os instrumentos propiciados pelas novas

21 Para um aprofundamento desses aspectos, cf. Oksaar (1988), Hoffmann (1988), Baumann e Kalverkämper (1992 e 2004), Stolze (1999), Garrido (2001), Kalverkämper (2001), Reichmann (2005; 2009), entre outros.

22 Por exemplo em Kalverkämper (2001) e Roelcke (2005).

23 Cf. Azenha (1999) e Aubert (2001). 
tecnologias. Não me refiro apenas a instrumentos de pesquisa e controle, quer dizer, ao uso de fontes no ambiente eletrônico e mediático (dicionários especializados, glossários, documentos e bases de dados disponibilizados online), mas também à espantosa evolução da linguística de corpus e de suas múltiplas aplicações nos Estudos de Tradução baseados em corpora. Nesse domínio, parecem estar dadas, enfim, todas as condições para o deslocamento definitivo do foco da atenção na transferência cultural de textos de especialidade: do domínio exclusivo do léxico para o "texto-em-situação", conforme já preconizam em meados dos anos de 1970 os mentores da Skopostheorie alemã.

E não apenas isso. As extensas varreduras que os instrumentos da linguística de corpus são capazes de fazer, associadas ao modo de exibição e de confronto dos resultados (alinhamentos de corpora paralelos, por exemplo) e aos mecanismos de busca e de aferição de relações (por exemplo, no confronto entre o texto traduzido e corpora de referência), permitem o estabelecimento de redes de relações até então só possiveis em domínios muito restritos. Tais redes encontram aplicação não apenas nos mecanismos de controle e de avaliação da transferência cultural de textos de especialidade, mas também em áreas correlatas, duas delas sendo os estudos linguísticos contrastivos para pares de línguas específicos e a formação de tradutores ${ }^{24}$.

Quanto à primeira, não é difícil ver que dessa interação resultam impactos positivos, por exemplo, para a constituição de gramáticas contrastivas e para a lexicografia bilingue ${ }^{25}$, desde que o observador esteja apto a interpretar devidamente os dados disponibilizados pelos instrumentos de busca e de organização. Além disso,

os resultados de análises contrastivas com diferentes pares lingüísticos têm contribuído de forma importante para a lingüística e para a tradução especializada nas áreas da pesquisa, do ensino e da prática da tradução, dado que grande parte dos textos traduzidos por tradutores profis-

24 Por exemplo, em Diaz (2004).

25 Para este tópico, cf. Baumann e Kalverkämper (1992; 2004), Reichmann (2005) e Herget e Proschwitz (2008).

TradTerm, 16, 2010, p. 37-66 
sionais são textos especializados. Em muitos estudos não são analisados somente os termos técnicos, pragmáticos e interculturais e elementos textuais (em relação à tipologia textual), sempre tendo em vista o texto como um todo (Fluck, 2005:73). Os resultados evidenciam diferenças terminológicas, fraseológicas, estruturais e estilisticas que permitem refletir de maneira fundamentada sobre formas adequadas de tradução (Reichmann, 2009:105)

Quanto à formação de tradutores, a lida com o meio eletrônico em suas múltiplas aplicações parece trabalhar favoravelmente no sentido tanto de incrementar, sob a perspectiva contrastiva dos usos linguísticos, a relação entre ensino (e aprimoramento de conhecimentos) de língua estrangeira e ensino de tradução ${ }^{26}$, quanto no sentido de corrigir uma distorção atestada pela experiência em sala de aula e já mencionada por mais de uma vez ao longo deste artigo: a de que o desconhecimento acerca dessa trajetória mais recente dos Estudos da Tradução voltados para as linguagens de especialidade garante a sobrevivência de uma visão herdada que ainda separa a tradução (e os tradutores) dessas duas vertentes. Nesse sentido, a sala de aula de tradução pode se transformar num centro, no qual se entrecruzam contribuições advindas da pesquisa sobre o ensino de línguas estrangeiras (por exemplo, na fase recepção, pelos alunos, do texto a ser traduzido), da linguística do texto especializado, da linguística de corpus e da terminologia variacional, tudo isso viabilizado pelo suporte do ambiente eletrônico.

Como vemos, as parcerias que vêm sendo seladas no curso da evolução dos Estudos da Tradução relacionados às linguagens de especialidade impõem ao tradutor, ao pesquisador e ao estudante de tradução, cada vez mais, um exercício de delimitação precisa da tarefa que se tem diante de si: se não é possível dominar tudo, só o estabelecimento de uma sequência de procedimentos, organizados por ordem de importância, é capaz de garantir não apenas a acuidade do resultado, mas também sua adequação aos propósitos específicos da tarefa proposta. Ao

26 Cf. por exemplo, Azenha (2006), Azenha e Nomura (2006) e Azenha e Nomura (2008). 
mesmo tempo, uma abordagem assim diversificada pode (e deve) incentivar o trabalho conjunto de profissionais de diferentes áreas, cada um deles exposto ao exercício de transpor os limites de suas áreas de especialidade no espaço multifacetado da tradução.

Antes de passarmos à seção seguinte, resta especular, por fim, se não teria início aqui um movimento contrário àquele que gerou a inclusão da noção de transferência cultural no domínio da tradução de linguagens de especialidade. Se, por questões de operacionalização, os novos instrumentos de busca e de tratamento dos textos de especialidade demandam sua fragmentação em unidades constitutivas menores, isso não exigiria do pesquisador, cada vez mais, a capacidade de reconstruir mentalmente o texto (e o discurso), a fim de analisar os casos isolados em função do conjunto? Se só isso é garantia de uma leitura eficaz nas diferentes dimensões do discurso de especialidade e, consequentemente, de uma "transferência cultural" eficaz desse tipo de discurso, sua não observância não marcaria um movimento de volta à consideração excessiva da dimensão "estritamente" linguística? E, a se levarem a cabo sistematicamente todas as pesquisas que buscam a comprovação dos chamados "universais de tradução" (Baker, 1993) - a simplificação e a explicitação, por exemplo - não estaríamos operando novamente rumo a uma concepção que defende os mecanismos de produção de sentido nas linguagens de especialidade em função de uma razão universalmente válida? Se é verdade que cada movimento evolutivo traz em si o germe de um movimento que lhe é contrário, parecem-me serem esses, em sintese, os desafios para as próximas décadas.

\section{Transferência cultural e textos literários}

No início dessas considerações, dissemos que o conceito de transferência cultural, que ganhou relevância no bojo da escola Funcional-Cultural dos Estudos da Tradução na Alemanha, foi encampado pelo Grupo de Göttingen e aplicado sistematicamente a estudos de caso, inspirados pelos Estudos Descritivos da Tradução e pela Teoria dos Polissistemas. Dissemos também

TradTerm, 16, 2010, p. 37-66 
que a noção é mais perceptivel (e também aceita) no domínio dos textos literários. Desse modo, daremos ênfase, nesta seção, menos à descrição de uma linha evolutiva, amplamente tratada na literatura pertinente ${ }^{27}$, e mais ao desafio de orientação a que se veem expostos estudantes e pesquisadores de tradução quando se ocupam dessa questão.

Cruz (2007:28ss.), na esteira de Hermans (1999), resenha as principais linhas de pesquisa e de atuação das vertentes citadas no parágrafo anterior e consensualmente tidas como fundadoras de uma perspectiva prospectiva e descritiva dos Estudos da Tradução de textos literários: a noção de sistema dinâmico, por oposição a um sistema estático (quer dizer, sincrônico) de relações, a historicidade do sistema (quer dizer, conjuntos diacrônicos em operação num mesmo e dado momento) e o sistema semiótico como estrutura aberta, heterogênea (um "polissistema", portanto, a ser entendido como um conjunto de sistemas heterogêneos em movimento e vinculados historicamente). Além disso, o autor elenca três pares de opostos que, segundo ele, garantem a dinâmica dos sistemas e definem relações de tensão continua, estimulada pela interferência de agentes: (1) produtos ou modelos canonizados e não canonizados, (2) centro e periferia do sistema e (3) atividades primárias ou inovadoras e secundárias ou conservadoras.

À semelhança do que vimos na seção anterior, portanto, a mudança de perspectiva basicamente põe por terra a ideia de uma rede estática de relações e atribui a tudo uma dinâmica incansável. Ao mesmo tempo, a noção de fluxo arrasta consigo também o sujeito-observador, que é retirado do conforto de uma posição à parte e acima do processo e trazido para o interior dessa torrente. A partir daí, não é dificil ver que essa dinâmica (e a desestabilização dela decorrente) demanda a criação de mecanismos de controle a serem aplicados a cada caso - seja isso no domínio do traduzir em si, seja no da reflexão sobre o processo -, já que as categorias em jogo aqui, ainda que definam uma moldura con-

27 Cf., por exemplo, Schulte e Biguenet (1992), Assmann (1995), Kopetzki (1996), Budick e Iser (1996) Hermanns (1998), Cortés (1999), Nush (2001), Munday (2001) e Snell-Hornby (2006). 
ceitual, são amplas demais para permitirem uma operacionalização imediata.

Diante de tal constatação, e a fim de se viabilizar um estudo concreto e condizente com tal perspectiva, o primeiro desafio diz respeito à conjugação de conceitos e métodos advindos de diferentes áreas de estudo ${ }^{28}$. Não apenas uma justaposição de etapas que possibilite a criação de uma ponte entre o geral e o específico, mas também - e sobretudo - uma conjugação de procedimentos articulados e sintonizados entre si do ponto de vista teórico. E, aqui, a especificidade do discurso literário pode ser o ponto de partida para a definição de alguns suportes teóricometodológicos dos Estudos da Tradução.

É consenso que, no discurso literário, a dimensão criativa da linguagem é considerada eixo de sustentação de um ponto de vista a partir do qual o mundo é lido, reconstruído discursivamente e os personagens são criados. Nesse processo, o emprego peculiar, por vezes inusitado, de recursos linguísticos e nãolinguístico ${ }^{29}$ assume um duplo papel: ele não apenas empresta corpo e voz a personagens e situações, como também remete a um ponto de vista, a um olhar que observa e analisa o mundo de um ângulo personalíssimo. Ao fazê-lo, ele sela vínculos com seu entorno e com a cultura que lhe serve de moldura, e é a partir desse compromisso que a própria noção de transferência cultural em textos literários se redimensiona: se reconhecivel e aceita para categorias privilegiadas como a dos substantivos, o conceito de marca (ou marcador) cultural em textos literários tende facilmente a se volatizar e a se dispersar, por assim dizer, por toda a tessitura discursiva. Como decorrência disso, a questão da leitura, da recepção por parte daquele que se ocupa do texto literário com os óculos da tradução se desdobra do mero entretenimento, da mera fruição, para a identificação e análise desses usos linguísticos significativos que sustentam uma visão de mundo, uma ideologia, entendida esta última em seu sentido lato.

28 Crisafulli (2002) fala da necessidade de se criarem modelos "ecléticos" para a metodologia.

29 Refiro-me, aqui, à interação texto-imagem, por exemplo na literatura escrita para a criança e o jovem.

TradTerm, 16, 2010, p. 37-66 
Se pensarmos, então, em instrumentos que nos auxiliem na identificação e no tratamento dessa dimensão criativa, muitas vezes plástico-poética da linguagem, veremos que se faz indispensável uma incursão pelos dominios de áreas afins: a teoria literária, por exemplo, os modelos e métodos de análise do discurso literário, o recurso à História, entre outros. Na verdade, isso nada mais significa que, mesmo operando no interior de uma perspectiva descritiva e prospectiva dos Estudos da Tradução, os olhos se voltem "retrospectivamente" para uma consideração mais atenta do texto de partida ${ }^{30}$. Só assim, e contando com o apoio de um instrumental proveniente de áreas afins, o texto-objeto da tradução poderá ser recontextualizado e os pontos identificados, a partir dos quais o ângulo de observação, a leitura empreendida pelo tradutor será validada.

A partir daí, o centro de interesses se desloca para a recepção: é preciso traçar uma estratégia de trabalho que considere, de um lado, recursos linguísticos distintos na língua e na cultura de chegada e a necessidade de adaptações que levem em conta as diferenças entre os sistemas; de outro, os propósitos editoriais que coatuam na definição das escolhas, no sentido de privilegiarem uma orientação de leitura, de revelarem um aspecto da obra (e do autor) que, validadas por um estudo descritivo e contextual, deverá prevalecer no trabalho de "transferência cultural". Nesse ponto, e à semelhança do que dissemos acerca da transferência cultural em textos de especialidade, também para a tradução de literatura o ponto de partida parece ser a definição de um objetivo, de uma função para o texto traduzido. E ainda que a escola funcional e cultural dos Estudos da Tradução possa oferece um suporte para isso, a mera definição da função atua apenas como um farol a ser seguido, mas não elimina a necessidade de se buscarem outros instrumentos de abordagem para a reconstituição do plano mais específico do texto e do discurso. Assim, se na fase de recepção pelo tradutor (ou pesquisador) do texto a ser traduzido (ou analisado) foi necessário lançar mão de recursos que construíssem uma ponte entre a orientação geral e o caso específico, o mesmo se dá agora, na fase de retextualização com vistas à recepção pelo leitor.

30 Cf. Koller (1998).

TradTerm, 16, 2010, p. 37-66 
De volta à visão prospectivo-descritiva - o "segundo momento" a que nos referimos nas considerações iniciais -, os trabalhos inaugurais de Toury e Even-Zohar, desenvolvidos em Israel paralelamente aos de Reiss e Vermeer na Alemanha, podem sensibilizar para questões importantes acerca do impacto da literatura traduzida sobre o sistema literário de recepção: ali estão esboçados mecanismos de acomodação, normas que buscam sistematizar a atuação de agentes ${ }^{31}$, bem como um panorama de relações existentes no interior do sistema literário e de seus subsistemas. Ainda assim, trata-se de relações de grande amplitude, que precisam ser complementadas por outros procedimentos até sua operacionalização.

Essa parece ter sido a preocupação central do chamado "Grupo de Göttingen" (Sonderforschungsbereich 309: Die literarische Übersetzung), atuante entre 1985 e 1997. Uma amostra dos trabalhos do grupo está em Translating literatures, translating cultures, livro editado por Kurt Mueller-Vollner e Michael Irmscher, em 1998. Trata-se de uma coletânea de conferências ministradas em 1995 em Standford (EUA). Em sintonia com a mudança de paradigma mencionada anteriormente, trata-se de pesquisas de natureza histórico-descritiva, que visam a analisar o impacto de traduções na formação cultural, na produção literária "local", entre outros objetivos, conforme destaca Frank (1998:16).

Da descrição do artigo de Kittel (1998:7ss.) sobre os objetivos do grupo se podem citar (1) explorar sistematicamente a história da tradução literária (com especial enfoque para a tradução ao alemão) desde o início do séc. XVIII, (2) examinar, categorizar e, se possivel, explicar diferenças linguísticas, semânticas e hermenêuticas entre os textos de partida e de chegada e (3) como consequência de sua [do Grupo] orientação históricofilológica, observar instâncias históricas de concepções prescritivas, sem se arvorar em oferecer soluções definitivas para problemas tão antigos.

Vemos, aqui, que ajustes tiveram de ser feitos nas categorizações inicialmente desenvolvidas pelas perspectivas respon-

31 Por exemplo, em Bandia e Milton (2009).

TradTerm, 16, 2010, p. 37-66 
sáveis pela mudança de paradigma. Por se tratar de estudos detalhados de caso (a exemplo, também do que se pratica no âmbito dos Estudos Descritivos da Tradução nos EUA e nos Países Baixos), foi preciso combinar uma abordagem histórico-descritiva com o objetivo de estudar a recepção, o (polis-)sistema. Contudo, e em decorrência dessa tentativa de aplicação de preceitos genéricos, o Grupo não centrou seus esforços apenas no lado "prospectivo", receptivo, mas - num procedimento análogo ao que descrevemos há pouco - levou em conta também o textofonte do ponto de vista linguístico, semântico e hermenêutico. Em poucas palavras: buscou um "caminho do meio". Como o objetivo do Grupo era estudar a contribuição da literatura traduzida para a formação de uma identidade nacional, Kittel (1998) justifica assim a adoção dessa perspectiva:

o que acontece com o texto traduzido no contexto da cultura receptora é meramente um aspecto do fenômeno complexo de transferência interlingual, interliterária e intercultural. (Kittel, 1998:7)

Além disso, a interdisciplinaridade revelou-se elemento constituinte do projeto: pesquisaram-se a prosa e o drama (com enfoque especial para os sécs. XVIII e XIX), o que - levado a cabo sistematicamente em diversas vertentes dos Estudos da Tradução - aponta para um crescente esmaecimento das fronteiras desse campo disciplinar: menos uma compartimentação e mais uma cooperação interdisciplinar ${ }^{32}$. A fim de viabilizar isso, o Grupo retoma várias linhas do pensamento sobre a tradução, tal como desenvolvido no Classicismo e no Romantismo alemães: as "escavações" do passado (aspecto filológico), o vínculo da reflexão sobre a linguagem com a História, os conceitos cambiantes do que é "próprio" ou "correto" em tradução, o estudo sistemático e a tradução praticada à larga como elemento constituinte de uma identidade, a experiência da alteridade na formação

32 Um correlato da "nova orientação" dos Estudos da Tradução empreendida no ambiente de expressão alemã principalmente por SnellHornby. 
$(\text { Bildung })^{33}$. Donde podemos pensar que, mesmo ancorados historicamente em outros momentos da reflexão sobre tradução na História, esses trabalhos fazem ressurgir agora, numa roupagem, digamos, mais política, a questão da visibilidade do tradutor $^{34}$, de um lado, e a reflexão sobre o impacto da literatura traduzida na geopolítica dos sistemas receptores, de outro.

A partir desse ponto, as possibilidades de detalhamento se multiplicam. Trabalhos análogos e desenvolvidos especificamente para o tratamento no nivel textual e discursivo de textos literários em tradução podem ser encontrados em Lèvy (1969), Berman (2007; $1^{\text {a }}$ ed. 1985) e Meschonnick (1985), apenas para citar três exemplos ${ }^{35}$. À semelhança dos estudos de caso empreendidos pelo Grupo de Göttingen, o trabalho desses autores - e de outros - está, por assim dizer, a meio caminho entre um olhar retrospectivo, voltado para a dimensão poética do texto-fonte, e também prospectivo, isto é, voltado para os mecanismos de recepção. Em todos os casos, trata-se de estudos que enfocam procedimentos de tradução, buscam conciliar teoria e prática e combinam métodos linguísticos e literários.

Parece ser este, em sintese, o desafio que se coloca aqui: a adoção de um paradigma contemporâneo dos Estudos da Tra-

33 Assim dirigidos, os estudos de caso propuseram, inclusive, releituras e revisões do que as antologias dizem sobre a tradução nos sécs. XVIII e XIX na Alemanha. Por exemplo, a tradução, no séc. XVIII, de textos ingleses ao alemão, via francês. Isso contraria a noção de que naquele século, na Alemanha, se praticava exclusivamente um tipo de tradução estritamente filológica, de que são exemplos os trabalhos de Wieland (1733-1813), tradutor de Shakespeare, e Hölderlin (1770-1843), tradutor de Sófocles. Sobre a tradução de Sófocles empreendida por Hölderlin, cf. Campos (1969).

34 Em Lèvy (1969), por exemplo, o método ilusionista vs. método antiilusionista: o tradutor "escondido" atrás do original, ou explicitamente presente. O trabalho de Lèvy traz paralelos com os conceitos de "covert translation" e "overt translation" de Juliane House (1981) e com toda a questão desenvolvida por Venuti (1995) sobre a visibilidade e a invisibilidade do tradutor.

35 A fim de não extrapolar os limites deste artigo, deixo de lado propositadamente a questão específica da tradução poética.

TradTerm, 16, 2010, p. 37-66 
dução para o tratamento dos textos literários não exclui a diacronia, a retomada de concepções desenvolvidas anteriormente ao momento da virada, mas nos impõe a todos, isso sim, uma releitura contextualizada dessas concepções à luz das novas exigências. Não a adoção pura e simples, portanto, de um modelo de tratamento e análise, mas a conjugação de perspectivas concorrentes e complementares, num sistema de retroalimentação constante. Não o descarte puro e simples de concepções consideradas ultrapassadas, mas a sua atualização em função de um objetivo específico e dos avanços verificados em áreas afins. Só sob essa perspectiva interativa, que promove recortes e os coaduna à luz de um objetivo, é que podemos entender os movimentos de ir e vir detectados nas concepções sobre a tradução e o traduzir ao longo dos tempos e muitas vezes reduzidos inadvertidamente a dicotomias, a categorias excludentes.

\section{Considerações finais: a estratégia da transparência}

$\mathrm{Na}$ busca de um estrato comum em que a noção de transferência cultural possa ser empregada tanto para textos de especialidade, quanto para os literários - um espaço da tradução e do traduzir como um todo -, reportamo-nos primeiramente às décadas de 1970 e 1980 e a uma mudança de paradigma que ficou conhecida como "virada cultural". Do encontro com esse momento e da contextualização dessa mudança pode-se derivar diretrizes que, se são capazes de definir um ângulo de observação e uma moldura conceitual, de um lado, por outro operam com categorias de grande amplitude, e trazem consigo o desafio, para o tradutor e o pesquisador de tradução, de construir um aporte teórico-metodológico condizente com um objetivo e uma tarefa no caso específico.

Se a definição da estratégia é vista aqui como um elemento unificador, negociado, de uma série de condicionantes, a contrapartida disso é o fato de essa estratégia não se concretizar num único caminho. A definição do objetivo e a consciência das condicionantes reabilitam as diretrizes fundamentais da Skopostheorie e somam à competência tradutória a habilidade de conjugar procedimentos: até a concretização da estratégia, o 
60

processo pressupõe a conjugação de recursos e recortes advindos das áreas afins, quer dizer, limítrofes ao estudo específico, tudo isso num processo de contínua retroalimentação. Nesse sentido, transparência há que ser entendida aqui como definição clara de critérios que nortearam as escolhas como um todo (e não apenas em pontos isolados), visto que o discurso, se de especialidade ou literário, se constitui no conjunto e não pode ser reduzido às suas partes constitutivas tomadas isoladamente.

Assim, embora deslocado para a recepção, o objetivo do trabalho específico - seja no domínio da tradução de literatura, seja no da tradução de linguagens de especialidade - não perde de vista o olhar "retrospectivo" para o texto de partida e sua contextualização, inclui um planejamento de acomodação de recursos linguístico-estilísticos no plano discursivo, conjuga interesses de agentes intervenientes no processo de produção (inclusive, se for o caso, no que respeita a recursos não-verbais) e garante, assim, um desenrolar mais coerente do trabalho até o receptor. E isso significa que, embora atuando num ambiente prospectivo e descritivo, a mirada retrospectiva, voltada às condições de produção do texto-fonte, pode ser entendida como um ponto de partida pleno de informações relevantes.

Nesse sentido, as estratégias da transparência, que estão associadas à questão da visibilidade do tradutor - e, no limite, a uma questão ética -, podem ganhar espaço, por exemplo, em notas preliminares, prefácios e posfácios, além de inclusões no corpo do texto (paráfrases, expansões, observações parentéticas). A conquista de tais espaços não é tarefa fácil, sobretudo na tradução de textos de especialidade, cujos espaços de visibilidade, dada a natureza mesma desse tipo de comunicação, são menores, embora não ausentes. Desse modo, se, de um lado, a (difícil) conquista desses "espaços de explicação" requer negociação, por outro, já não é sem tempo que isso precisa acontecer. Se é consenso que notas explicativas inseridas no discurso literário destroem a dimensão ficcional, pois remetem o leitor ao plano da metalinguagem, também é verdade que, para os textos de especialidade, o mesmo se aplica. Afinal, não é possível ignorar todos os avanços obtidos nos Estudos da Tradução acerca dessa questão. E é função social do tradutor - literário ou não - contri-

TradTerm, 16, 2010, p. 37-66 
buir para uma aproximação entre o que se desenvolve no plano dos estudos e o que se considera lícito nas esferas editorial e empresarial.

Por fim, só a atitude de colocar em prática um saber construído, e fazê-lo de forma clara, é capaz de aproximar a condição profissional de tradutores iniciantes no domínio da tradução com a de nomes já consagrados que, como sabemos, costumam dominar certas faixas do mercado de trabalho e nem sempre agraciam seus leitores-receptores com um resultado aceitável.

\section{Referências bibliográficas}

ASSMANN, A. (1995) Was sind kulturelle Texte? In: POLTERMANN, A. (orgs.) - Literaturkanon - Medienereignis - kultureller Text: Formen interkultureller Kommunikation und Übersetzung. Berlin: Erich Schmidt Verlag, pp. 232-244.

AUBERT, F. H. (2001) Tradução técnico-científica e terminologia: um ensaio exploratório. In: ALVES, I. (org.) - TradTerm. São Paulo: Humanitas, n. 7, pp. 41-52.

AZENHA JUNIOR, J. (1994) Aspectos culturais na produção e na tradução de textos técnicos de instrução alemão-português: teoria e prática. Tese de Doutorado. São Paulo.

(1999) Tradução Técnica e Condicionantes Culturais. Primeiros Passos para um Estudo Integrado. São Paulo: Humanitas.

(2006) O lugar da tradução na formação em Letras: algumas reflexões. Cadernos de Tradução. Florianópolis, vol. 17, pp. 157-188.

AZENHA JUNIOR, J.; NOMURA, M. (2006) Textproduktion im Deutschunterricht für Anfänger. Dafbrücke. Curitiba, vol. 7, pp. 30-32. (2008) Tópicos de morfossintaxe relevantes para a tradução alemão-português: literalidade e idiomaticidade no processo de tradução. In: BATTAGLIA, M.H.V.; NOMURA, M. (eds.) Estudos lingüísticos contrastivos em alemão e português. São Paulo: Annablume/FAPESP, pp. 133-149.

BAKER, M. (2001) Routledge Encyclopedia of Translation Studies. London: Routledge.

BANDIA, P.; MILTON, J. (eds.) (2009) Agents of Translation. Amsterdam, Philadelphia: John Benjamins Publishing Company.

TradTerm, 16, 2010, p. 37-66 
BARBOSA, H. G. (2004) Procedimentos técnicos da tradução. Uma nova proposta. Campinas (SP): Pontes, $2^{\mathrm{a}}$ ed.

BAUMANN, K.-D.; KALVERKÄMPER, H. (eds.) (1992) Kontrastive Fachsprachenforschung. Tübingen: Narr. (eds.) (2004) Pluralität in der Fachsprachenforschung. Tübingen: Narr.

BERMAN, A. (2007) A tradução e a letra ou o albergue do longínquo. Rio de Janeiro: 7Letras/PGET Tradução de Marie-Hélène Catherine Torres, Mauri Furlan e Andréia Guerrini. Tradução da edição francesa de 1985.

BESSA, C. R. (2003) A tradução de rótulos de comestiveis e cosméticos. Brasilia: UnB, Oficina Instituto de Letras.

BUDICK, S.; ISER, W. (eds.) (1996) The Translatability of Cultures. Figurations of the Space Between. Stanford: Stanford University Press,

BUSH, P. (2001) Literary Translation: Practices. In: BAKER, M. Routledge Encyclopedia of Translation Studies. London: Routledge, pp. 127130.

CABRÉ, M. T., FREIXA, J., LORENTE, M.; TEBÉ, C. (1998) La terminologia hoy: replanteamiento o diversificación. In: KRIEGER, M.G. (org.) Terminologia e integração. Organon 26 - Revista do Instituto de Letras da Universidade Federal do Rio Grande do Sul. Porto Alegre: Faculdade de Filosofia, vol. 12, n. 26, pp. 33-41.

CAMPOS, H. (1969) A palavra vermelha de Hölderlin. In: CAMPOS, H. $A$ arte no horizonte do provável. São Paulo: Perspectiva.

CARDOSO, M., HEIDERMANN, W.; WEININGER, M. (eds.) (2009) A Escola Tradutológica de Leipzig. Frankfurt a.M.: Peter Lang.

CATFORD, J. C. (1980) - Uma teoria lingüistica da tradução. São Paulo: Cultrix; Campinas (SP): PUC, Tradução do Centro de Especialização de Tradutores do Inglês do Instituto de Letras da PUC-Campinas.

CORTÉS, O. C. (1999) Traducción y Cultura. De La ideologia ao texto. Salamanca: Ediciones Colegio de España y Ovidi Carbonell i Cortés.

CRISAFUlLI, E. (2002) The Quest for an Ecletic Methodology of Translation Description. In: HERMANS, T. (ed.) - Crosscultural transgressions. Research models in Translation Studies II. Historical and Ideological Issues. Manchester, Northhampton: St. Jerome Publishing, pp. 26-43.

CRUZ, C. (2007) Metamorfoses de Kafka. São Paulo: AnnaBlume/ FAPESP.

TRAdTerm, 16, 2010, p. 37-66 
DIAZ, O. (2004) Novas ferramentas para (ensinar a) traduzir. In: GARRIDO, C. (org.) Ferramentas para a traduçom. Ourense: Associaçom Galega da Língua, pp. 143-171.

EVEN-ZOHAR, I. (1978) Papers in Historical Poetics. Tel Aviv: Porter Institute, Tel Aviv University. (1990) Polysystem Theory. Poetics Today, vol. 1: 1-2.

FLUCK, H.-R. - Fachsprachenforschung. In: SNELL-HORNBY et al (orgs.) Handbuch Translation. Tübingen: Stauffenburg, pp. 72-77.

FRANK, A.P. (1998) Schattenkultur and Other Well-Kept-Secrets: from Historical translation Studies to Literary Historiography. In: MUELLER-VOLLMER, K. e IRMSCHER, M. (1998), pp. 15-30.

FAULSTICH, E. (2001) Aspectos de terminologia geral e terminologia variacionista. In: ALVES, I. (org.) - TradTerm. São Paulo: Humanitas, n. 7 , pp. 11-40.

GARRIDO, C. (2001) Aspectos teóricos e prácticos da traduçom científico-técnica (inglês.galego). Ourense: Associaçom Galega da Língua.

HEIDERMANN, W. (org.) (2001) Clássicos da Teoria da Tradução (Antologia Bilíngüe, vol. 1, alemão-português). Florianópolis: UFSC, Núcleo de Tradução.

HERGET, K.; PROSCHWITZ, H. (2008) Übersetzung deutscher Komposita ins Portugiesische. Sprachkonventionen in der Technik. Forum Sprache, MDÜ 3, pp. 34-38.

HERMANS, T. (1998) Descriptive Translation Studies. In: SNELLHORNBY et al (orgs.) Handbuch Translation. Tübingen: Stauffenburg, pp. 96-100.

HERMANS, T. (1999) Translation in systems: descriptive and systemoriented approaches explained. Manchester: St. Jerome Publishing.

HOFFMANN, L. (1988) Vom Fachwort zum Fachtext. Beiträge zur Angewandten Linguistik. Tübingen: Narr.

HOUSE, J. (1981) A model for translation quality assessment. 2a ed. Tübingen: Narr.

KALVERKÄMPER, H. (2001) Fachsprachen. Langues de spécialité. In: HOLTUS, G., METZELTIN, M.; SCHMiTT, C. (eds.) Lexikon der Romanistischen Linguistik. Band I, 2. Tübingen: Max Niemeyer, pp. 349-307.

KITTEL, H. (1998) Inclusions and Exclusions: The "Göttingen Approach" to Translation Studies and Inter-Literary History. In: MUELLERVOLLMER, K.; IRMSCHER, M., 3-13. 
KOCH, I.V. (2004) Introdução à Lingüística Textual. São Paulo: Pontes. KOLLER, W. (1988) Die literarische Übersetzung unter linguistischem Aspekt. Bedingungsfaktoren der Übersetzung am Beispiel Henrik Ibsens. In: KITTEL, H. (ed.) Die literarische Übersetzung. Stand und Perspectiven ihrer Forschung. Mit einer Einleitung von Armin Paul Frank. Berlin: Erich Schmidt Verlag (Göttinger Beiträge zur Internationalen Übersetzungsforschung (Band 2), pp. 64-91.

KOPETZKI, A. (1996) Beim Wort nehmen. Sprachtheoretische und ästhetische Probleme der literarischen Übersetzung. Stuttgart: M und $P$, Verl. für Wiss. und Forschung.

KRIEGER, M.G. (org.) Terminologia e integração. Organon 26 - Revista do Instituto de Letras da Universidade Federal do Rio Grande do Sul. Porto Alegre: Faculdade de Filosofia, vol. 12, n. 26.

KRIEGER, M.G.; MACIEL, A.M.B. (orgs.) (2001) Temas de Terminologia. Porto Alegre/São Paulo: Editora da Universidade/UFRGS/ Humanitas/USP.

KRIEGER, M.G.; FINATTO, M.J.B. (2004) Introdução à Terminologia: teoria e prática. São Paulo: Contexto.

LADMIRAL, J.-R. (1979) Traduzir: teoremas para a tradução. Paris: Editions Payot.

LEVÝ, J. (1969) Die literarische Übersetzung. Theorie einer Kunstgattung. Frankfurt am Main, Bonn: Athenäum Verlag.

MAILLOT, J. (1975) A tradução científica e técnica. São Paulo: McGrawHill do Brasil; Brasília: Ed. da Universidade de Brasília. Trad. Paulo Rónai.

MESCHONNIC, H. (1985) Les Tours de Babel. Essais sur la traduction. Mauvezin: Trans-Europ-Repress.

MOUNIN, G. (1975) Os problemas teóricos da tradução. São Paulo: Cultrix, Tradução de Heloysa de Lima Dantas.

MUNDAY, J. (2001) - Introducing Translation Studies. Theories and Applications. London: Routledge.

MUELLER-VOLLMER, K.; IRMSCHER, M. (eds.) (1998) Translating Literatures, Translating Cultures. New Vistas and Approaches in Literary Studies. Stanford: Stanford University Press.

NORD, C. (1988) Textanalyse und Übersetzung. Theoretische Grundlagen, Methode und didaktische Anwendung einer übersetzungsrelevanten Textanalyse. Heidelberg: Julius Groos.

NORD, C. (1993) Einführung in das funktionale Übersetzen: am Beispiel von Titeln und Überschriften. Tübingen; Basel: Francke.

TRADTERm, 16, 2010, p. 37-66 
OKSAAR, E. (1988) Fachsprachliche Dimensionen. Tübingen: Narr.

REICHMANN, T. (2005) Satzspaltung und Informationsstruktur im Portugiesischen und im Deutschen. Ein Beitrag zur kontrastiven Linguistik und Übersetzungswissenschaft. Frankfurt am Main: Peter Lang.

(2009) Marcas culturais nas linguagens de especialidade. Lusorama, 77-78, pp. 103-122.

REISS, K. (1983) Texttyp und Übersetzungsmethode. Der operative Text. 2., unveränderte Auflage. Heldelberg: Groos.

REISS, K.; VERMEER, H. (1984) Grundlegung einer allgemeinen Translationstheorie. Tübingen: Niemeyer.

ROELCKE, T. - Fachsprachen. 2., durchgesehene Auflage. Berlin: Erich Schmidt.

SCHMiTT, P. A. (1986) - Die „Eindeutigkeit” von Fachtexten: Bemerkungen $z u$ einer Fiktion. In: SNELL-HORNBY, M. Übersetzungswissenschaft: eine Neuorientierung. Zur Integrierung von Theorie und Praxis. Tübingen: Francke, pp. 252-282.

SCHMITT, P.A. (1989) Kulturspezifik von Technik-Texten: Ein translatorisches und terminographisches Problem. In: VERMEER, H.J. (ed.) Kulturspezifik des translatorischen Handelns. Heidelberg: Universitätsdruckerei.

SCHUlTE, R.; BIGUENET, J. (eds.) (1992) Theories of Translation. An Anthology of Essays from Dryden to Derrida. Chicago, London: The University of Chicago Press.

SNELL-HORNBY, M. (1986) Übersetzungswissenschaft: eine Neuorientierung. Zur Integrierung von Theorie und Praxis. Tübingen: Francke.

(1988) Translation Studies: an integrated approach. Amsterdam, Philadelphia: John Benjamins Publishing Company.

(1989) Eine integrierte Übersetzungstheorie für die Praxis des Übersetzens. In: Königs, F.-G. - Übersetzungswissenschaft und Fremdsprachenunterricht. Neue Beiträge zu einem alten Thema. München: Goethe Institut, pp. 15-51.

(2006) The Turns of Translation Studies. New paradigms or shifting viewpoints? Amsterdam/Philadelphia: John Benjamins Publishing Company.

STOLZE, R. (1999) Die Fachübersetzung. Eine Einführung. Tübingen: Narr. 
66

TOURY, G. (1980) In Search of a Theory of Translation. Tel Aviv: Porter Institute, Tel Aviv University.

(1985) "A Rationale for Descriptive Translation Studies". In: HERMANS, T. (ed.) The Manipulation of Literature. Studies in Literary Translation. London: Croom Helm.

(1995) Descriptive Translation Studies and beyond. Amsterdam, Philadelphia: John Benjamins Publishing Company.

VENUTI, L. (1995) The Translators' Invisibility. A History of Translation. London: Routledge.

TradTerm, 16, 2010, p. 37-66 